\title{
Infliximab reverses steatosis and improves insulin signal transduction in liver of rats fed a high-fat diet
}

\author{
Raquel Barbuio, Marciane Milanski, Manoel B Bertolo, Mário J Saad and Lício A Velloso \\ Department of Internal Medicine and Gastrocentro, State University of Campinas, Campinas, SP 13083-970, Brazil \\ (Correspondence should be addressed to L A Velloso; Email: lavelloso@fcm.unicamp.br)
}

\begin{abstract}
Non-alcoholic fatty liver disease, induced by nutritional factors, is one of the leading causes of hepatic dysfunction in the modern world. The activation of proinflammatory signaling in the liver, which is induced by systemic and locally produced cytokines, and the development of hepatic insulin resistance are two important factors associated with the progression from steatosis to steatohepatitis, a pre-cirrhotic condition. The objective of the present study was to evaluate the effect of inhibition of tumour necrosis factor (TNF)- $\alpha$, using the monoclonal antibody infliximab, on the expression of cytokines, induction of steatosis and fibrosis, and insulin signal transduction in the liver of Wistar rats fed a high-fat
\end{abstract}

diet. Ten days of treatment with infliximab significantly reduced the expression of the proinflammatory markers, TNF- $\alpha$, IL-6, IL-1 $\beta$, and SOCS-3, in the liver of rats fed a high-fat diet. This was accompanied by reduced fat deposition and fibrosis and by improved insulin signal transduction through insulin receptor (IR)/IR substrate/Akt/FOXO1 and JAK2/STAT3 pathways. In conclusion, short-term inhibition of TNF- $\alpha$ with infliximab reduces inflammation and steatosis/fibrosis, while improving insulin signal transduction in an animal model treated with a high-fat diet.

Journal of Endocrinology (2007) 194, 539-550

\section{Introduction}

Non-alcoholic fatty liver disease (NAFLD) comprehends a large spectrum of clinicopathological conditions of the liver, ranging from steatosis to cirrhosis, and including steatohepatitis (NASH) and fibrosis (Browning \& Horton 2004). In several regions of the world, predominantly those that have adopted westernized diet standards, NAFLD has become the most common cause of abnormal liver function, leading, frequently, to severe hepatic insufficiency (Browning et al. 2004, Williams 2006). However, not all patients (and animal models) exposed to a high-fat diet progress from steatosis to the pre-cirrhotic conditions, NASH, and fibrosis, and the factors that predispose to this progression are not completely known (Day \& James 1998, Browning \& Horton 2004).

In recent years, the characterization of the frequent association between NASH and hepatic insulin resistance has opened a new venue for investigation in this field (Medina et al. 2004). In several tissues of the body, including the liver, insulin resistance may evolve as a consequence of proinflammatory signaling generated by cytokines produced by the enlarged adipose tissue in overnourished people (Hotamisligil 2006). These cytokines activate intracellular serine kinases capable of targeting and inhibiting key elements of the insulin signaling pathway (De Souza et al. 2005a, Hotamisligil 2006). In the liver, both systemic and locally produced cytokines are thought to play a role in the progression to NASH and, also, to favor the installation of hepatic insulin resistance (Tilg \& Diehl 2000, Anty et al. 2006, Poniachik et al. 2006, Tomita et al. 2006). Among these cytokines, tumour necrosis factor (TNF)- $\alpha$ seems to play a predominant role since it can simultaneously activate a program that coordinates the expression of other cytokines and promotes intracellular proinflammatory signaling (De Souza et al. 2005a, Hotamisligil 2006, Tomita et al. 2006).

In clinical practice, the inhibition of TNF- $\alpha$ activity is currently in use for the treatment of diseases such as rheumatoid arthritis, Crohn's disease, and psoriatic arthritis (Chang \& Lichtenstein 2006, Scott \& Kingsley 2006). The anti-TNF- $\alpha$ monoclonal antibody, infliximab, is one of the available drugs approved for human use and is employed by thousands of patients in the world (Scott \& Kingsley 2006). Some recent studies have evaluated the effect of TNF- $\alpha$ inhibiting approaches for the treatment of different inflammatory liver diseases, but the results are still controversial (Tilg \& Diehl 2000). For example, at least two studies have observed favorable responses to TNF- $\alpha$ inhibiting approaches in ethanol-induced liver injury in rodents (Iimuro et al. 1997, Yin et al. 1999). Conversely, in a group of 20 patients with alcoholic steatohepatitis, only the combined use of infliximab and prednisone resulted in some clinical improvement after 28 days of treatment (Spahr et al. 2002). Because consumption 
of fat-rich diets seems to play an important role in the pathogenesis of NAFLD and on its progression to NASH (Lieber et al. 2004, Zou et al. 2006), in the present study, we utilize an animal model fed on a high-fat diet to evaluate the effect of infliximab upon liver cytokine expression, morphology, and insulin signal transduction. The results show that, after a short period of treatment, significant reductions in proinflammatory markers in the liver are accompanied by reduced steatosis and fibrosis, and by improved insulin signal transduction.

\section{Materials and Methods}

\section{Antibodies, chemicals, and buffers}

The reagents for SDS-PAGE and immunoblotting were purchased from Bio-Rad. HEPES, phenylmethylsulfonyl fluoride, aprotinin, dithiothreitol, Triton X-100, Tween 20, glycerol, and BSA (fraction V) were from Sigma. ${ }^{125}$ I-protein $A$ and nitrocellulose paper (BA85, $0 \cdot 2 \mu \mathrm{m})$ were from Amersham. Amobarbital and human recombinant insulin (Humulin R) were from Lilly. The anti-TNF- $\alpha$ monoclonal antibody, infliximab, was from Centocor (Horsham, PA, USA). Anti-insulin receptor (IR; sc-711, rabbit polyclonal), anti-IR substrate 1 (IRS1; sc-560, rabbit polyclonal), anti-IR substrate 2 (IRS2; sc-8299, rabbit polyclonal), anti-JAK2 (sc278, rabbit polyclonal), anti-Akt (sc-1618, goat polyclonal), anti-phospho [ $\mathrm{Thr}^{183} / \mathrm{Tyr}^{185}$ JJNK (sc-6254, mouse monoclonal), anti-phosphotyrosine (pY) (sc-508, mouse monoclonal), anti-phospho $\mathrm{Ser}^{473} \mathrm{Akt}$ (sc-7985-R, rabbit polyclonal), anti-STAT3 (sc-7179, rabbit polyclonal), antiphospho $\left[\mathrm{Tyr}^{705}\right]$ STAT3, anti-FOXO1 (sc-11350, rabbit polyclonal), anti-phospho [Ser $\left.{ }^{256}\right]$ FOXO1 (sc-22158-R, rabbit polyclonal), anti-PGC-1 $\alpha$ (sc-5816, goat polyclonal), anti-HNF-4 $\alpha$ (sc-6556, goat polyclonal), anti-TNF- $\alpha$ (sc1350, goat polyclonal), anti-IL-1 $\beta$ (sc-7884, rabbit polyclonal), anti-IL-6 (sc-1265, goat polyclonal), anti-IL-10 (sc-1783, goat polyclonal), anti-SOCS-3 (sc-9023, rabbit polyclonal), and anti-actin (sc-10731, rabbit polyclonal) antibodies were from Santa Cruz Biotechnology (Santa Cruz, CA, USA).

\section{Experimental model and treatment protocols}

Six-week-old male Wistar rats (Rattus norvegicus) from the University of Campinas Central Animal Breeding Center were used in the experiments. The rats were allowed access to chow and water ad libitum. The animals were maintained on a $12 \mathrm{~h}$ light: $12 \mathrm{~h}$ darkness artificial cycle and housed in individual cages. Food was withdrawn $12 \mathrm{~h}$ before the experiments. The investigation followed the University guidelines for the use of animals in experimental studies and conforms to the Guide for the Care and Use of Laboratory Animals published by the US National Institutes of Health (NIH publication no. 85-23 revised 1996). Rats were treated either with a regular rodent chow or with a fatrich (HL) diet (Table 1). The HL diet was prepared using predominantly fat from pork source and is rich in saturated fat (Araujo de Vizcarrondo et al. 1998). At 0 and 35 days after introduction of diets, rats were evaluated for metabolic parameters (Table 2). In the first part of the study, some rats were randomly selected at $5,10,15,20,25,30$, or 35 days after introduction of diets, for evaluation of liver histology and expression of cytokines, cytokine-responsive protein, and proteins involved in liver metabolism. After setting 20 days of HL diet as the time when steatosis was installed and levels of cytokines in liver were increased, some rats were randomly selected for treatment with saline $(100 \mu \mathrm{l} /$ dose, i.p., twice a day) or with infliximab $(100 \mu \mathrm{g}$ in $100 \mu \mathrm{l}$ saline/dose, i.p., twice a day). The infliximab dose was adjusted for rat metabolic rates, as compared with human metabolic rates (in clinical practice the human dose is $5 \cdot 0-10 \cdot 0 \mathrm{mg} / \mathrm{kg}$ every 8 weeks). Since the half-life of immunoglobulin is about $2-3$ weeks, we believe that treating the experimental animals on a daily basis leads to stable anti-TNF- $\alpha$ immunoglobulin levels at about 7 days of treatment. In this part of the study, the experiments were conducted 10 days after starting infliximab use (which corresponded to day 30 of HL diet introduction). In addition, to evaluate the effect of infliximab to inhibit TNF- $\alpha$ signaling, we performed a dose-response experiment. For that, rats were treated once, i.p., with different doses of the drug $(0,10,50,100,200$, and $400 \mu \mathrm{g}$ in $100 \mathrm{ml}$ saline), and after $24 \mathrm{~h}$, liver was obtained for evaluation of JNK activation by immunoblot as described later.

\section{Determination of glucose, insulin, leptin, and TNF- $\alpha$}

Glucose was determined by the glucose oxidase method, as previously described (Trinder 1969). Insulin was determined by RIA as described (Scott et al. 1981). Leptin was determined using a commercially available ELISA kit (Crystal Chem. Inc., Chicago, IL, USA), following the recommendations of the manufacturer. TNF- $\alpha$ was determined using a commercially available ELISA kit (Pierce Biotechnology Inc., Rockford, IL, USA), following the instructions of the manufacturer.

\section{Liver histology}

Hydrated $5 \mu \mathrm{m}$ sections of paraformaldehyde-fixed, paraffinembedded liver specimens were stained by regular

Table 1 Macronutrient composition of the diets

\begin{tabular}{|c|c|c|c|c|c|c|}
\hline & \multicolumn{3}{|c|}{ Standard chow } & \multicolumn{3}{|c|}{ High-fat chow } \\
\hline & $\overline{\mathrm{g} \%}$ & & $\mathrm{~kJ} \%$ & $\mathrm{~g} \%$ & & $k J \%$ \\
\hline Protein & 19 & & 18 & 19 & & 12 \\
\hline Carbohydrate & 77 & & 73 & 45 & & 27 \\
\hline Saturated fat & 4 & & 9 & 36 & & 61 \\
\hline $\mathrm{kJ} / \mathrm{g}$ & & $15 \cdot 8$ & & & $24 \cdot 5$ & \\
\hline
\end{tabular}


Table 2 Clinical, biochemical, and hormonal parameters of experimental animals

\begin{tabular}{|c|c|c|c|c|}
\hline & \multicolumn{2}{|l|}{ Control } & \multicolumn{2}{|l|}{ HL } \\
\hline & D0 & D35 & D0 & D35 \\
\hline Body mass (g) & $156 \pm 11$ & $212 \pm 18^{*}$ & $154 \pm 13$ & $276 \pm 22^{*,+}$ \\
\hline Glucose (mg/dl) & $91 \pm 6$ & $95 \pm 5$ & $92 \pm 7$ & $97 \pm 7$ \\
\hline Insulin (ng/ml) & $2 \cdot 45 \pm 0 \cdot 44$ & $2 \cdot 48 \pm 0 \cdot 46$ & $2 \cdot 42 \pm 0 \cdot 31$ & $3 \cdot 35 \pm 0 \cdot 33^{*,+}$ \\
\hline Leptin (ng/ml) & $2 \cdot 88 \pm 0 \cdot 23$ & $3 \cdot 01 \pm 0 \cdot 19$ & $2 \cdot 79 \pm 0 \cdot 22$ & $3 \cdot 97 \pm 0 \cdot 32^{*,+}$ \\
\hline
\end{tabular}

$n=5 ; * P<0.05$ vs D0 of the same group; ${ }^{+} P<0 \cdot 05$ vs D35 of control. D0, day 0 of treatment; D35, day 35 of treatment.

hematoxylin-eosin (HE) and Masson's trichrome (MT) methods for evaluation of liver histology and fibrosis (Lin et al. 1998).

\section{Liver glycogen and lipid content}

At the end of the experimental period, five rats from each experimental group were randomly selected for determination of glycogen and total lipid content in the liver. For that, fragments of liver were collected and digested in pre-warmed $\mathrm{KOH}$ solution (30\%) for glycogen measurements as previously described (Pimenta et al. 1989). Total lipid was determined by the gravimetric method (Mackenzie et al. 1970).

\section{Morphometric analysis}

A point counting procedure was carried out using a microscope with a sampling stage and a semiautomatic advancer. In HE- or MT-stained sections, fat or fibrosis areas respectively were delimited using the Adobe Photoshop software, and the respective areas were quantified using an Optomax Image Analysis System (Optomax, Burlington, MA, USA). For each group, livers from five rats were prepared and stained, and six fragments from each liver were analyzed. Morphometric results are presented as area fractions (the percentage of specific counts in relation to the total number of counted points; Lin et al. 1998, Thirone et al. 2002).

\section{Immunoprecipitation and immunoblotting}

For evaluation of cytokine and protein content, the abdominal cavities of anesthetized rats were opened and fragments of liver $(3.0 \times 3.0 \times 3.0 \mathrm{~mm})$ were gently removed and immediately homogenized in solubilization buffer at $4{ }^{\circ} \mathrm{C}$ (1\% Triton X-100, $100 \mathrm{mmol} / \mathrm{l}$ Tris-HCl (pH 7·4), $100 \mathrm{mmol} / 1$ sodium pyrophosphate, $100 \mathrm{mmol} / 1$ sodium fluoride, $10 \mathrm{mmol} / 1 \mathrm{EDTA}, 10 \mathrm{mmol} / 1$ sodium orthovanadate, $2.0 \mathrm{mmol} / 1 \mathrm{PMSF}$, and $0.1 \mathrm{mg}$ aprotinin $/ \mathrm{ml})$. The protein concentration of the supernatants was determined by the Bradford dye-binding method. Samples containing $0.2 \mathrm{mg}$ protein extracts were separated by SDS-PAGE, transferred to nitrocellulose membranes and blotted with antibodies against TNF- $\alpha$, IL-1 $\beta$, IL-6, IL-10, phospho $\left[\mathrm{Thr}^{183} / \mathrm{Tyr}^{185} \mathrm{JJNK}, \mathrm{PGC}-1 \alpha, \mathrm{HNF}-4 \alpha, \mathrm{IR}, \mathrm{IRS} 1, \mathrm{IRS} 2\right.$,
Akt, FOXO1, JAK2, STAT3, and SOCS3. For evaluation of insulin signal transduction in liver, the abdominal cavities of anesthetized rats were opened and the animals were injected insulin $\left(100 \mu \mathrm{l}, 10^{-6} \mathrm{~mol} / \mathrm{l}\right)$ or saline $(100 \mu \mathrm{l})$ through the cava vein. After different intervals (described in Results), fragments $(3.0 \times 3 \cdot 0 \times 3 \cdot 0 \mathrm{~mm})$ of liver were excised and immediately homogenized in solubilization buffer as mentioned previously. Samples of total protein extracts containing $2.0 \mathrm{mg}$ protein were used for immunoprecipitation with antibodies against IR, IRS1, IRS2 or JAK2 at $4{ }^{\circ} \mathrm{C}$ overnight, followed by SDS/PAGE, transfer to nitrocellulose membranes, and blotting with anti-phosphotyrosine (pY) antibodies. Some samples were analyzed by direct immunoblotting using antibodies against phospho $\left[\mathrm{Ser}^{473}\right]$ Akt, phospho [Ser $\left.{ }^{256}\right]$ FOXO1, and phospho [Tyr $\left.{ }^{705}\right]-$ STAT3. Specific bands were labeled with ${ }^{125} \mathrm{I}$-protein $\mathrm{A}$, and visualization was performed by exposure of the membranes to RX-films (Velloso et al. 1993). Protein loading in gels was evaluated by Coomassie blue staining and by reblotting membranes with anti-actin antibody.

\section{Statistical analysis}

Specific protein bands present in the blots were quantified by digital densitometry (ScionCorp Inc., Frederick, MD, USA); areas of interest in liver histology were quantified by point counting (Optomax Image Analysis System). Means \pm s.e.m. obtained from densitometric scans, area measurements, and the values for blood insulin, leptin TNF- $\alpha$ and glucose, and body mass were compared by ANOVA (Tukey-Kramer or Dunnett, as appropriate) with post hoc test (Bartlett). A $P$ value of $<0.05$ was accepted as statistically significant. In time course experiments for determination of protein content and in morphometric analysis, the results were normalized by the values of the controls and expressed as fold variation.

\section{Results}

\section{Metabolic characteristics of the experimental animals}

Table 2 shows that 35 days of treatment with the HL diet promoted a significant increase in body mass and serum insulin, and leptin levels. No modification in glucose levels was detected in HL-treated rats. 


\section{HL diet leads to hepatic steatosis and fibrosis}

The livers of rats on HL diet were clearly steatotic (Fig. 1A-upper panels, HE). The intra-hepatocyte fat depots were predominant in the perivenular zone with extensions to the external areas of the lobule. Morphometric analysis revealed an increase of 19.3fold ( $\pm 2 \cdot 2$-fold; $P<0 \cdot 05, n=5$ ) in fat depot areas, as compared with the control. In MT-stained livers, fibrosis was observed predominantly in portal spaces with some extension toward centro-lobular zones (Fig. 1A-lower panels, MT). The morphometric analysis revealed an increase of 3.7-fold $( \pm 0 \cdot 6-$ fold; $P<0 \cdot 05, n=5$ ) in fibrotic areas in the livers of $\mathrm{HL}$ rats.

Time-dependent increase in cytokine expression in livers of HL rats

HL diet consumption led to a progressive increase in the expression of the pro-inflammatory cytokines, TNF- $\alpha$, IL-6, and IL- $1 \beta$, of the regulatory cytokine IL-10 and the cytokine suppressor protein, SOCS-3, in the livers of rats (Fig. 1B). These events were accompanied by the reduced expression of a transcription factor involved in the control of gluconeogenesis, HNF- $4 \alpha$, and the increased expression of a co-activator of transcription involved in the regulation of lipid metabolism and storage in hepatocytes, PGC-1 $\alpha$ (Fig 1C).

Infliximab reduces pro-inflammatory cytokine expression in livers of $H L$ rats

The efficiency of infliximab to inhibit TNF- $\alpha$ action was tested by two different methods. First, mice on HL diet were treated with a single dose of infliximab according to a dose-response protocol described under Materials and Methods section, and the basal activation of JNK was determined in liver. As shown in Fig. 2A, a dose as low as $50 \mu \mathrm{g}$ infliximab was capable of significantly inhibiting JNK. Secondly, the blood concentration of TNF- $\alpha$ was determined in mice submitted to a 10-day infliximab treatment protocol. Consumption of the HL diet promoted a significant increase of TNF- $\alpha$ blood levels from $76.3 \pm 6.9$ to $166 \cdot 0 \pm 9 \cdot 7 \mathrm{pg} / \mathrm{ml}$, in control and HL mice respectively $(n=5, P<0 \cdot 05)$. Upon infliximab treatment, the levels of TNF- $\alpha$ in HL mice reduced $35 \%$ to $107 \cdot 4 \pm 8 \cdot 1 \mathrm{pg} / \mathrm{ml}$ $(n=5, P<0.05$ versus HL not treated with infliximab; Table 3$)$. Infliximab did not promote significant changes in body mass, flood intake, and blood levels of insulin and leptin (Table 3). To evaluate the effect of TNF- $\alpha$ inhibition upon liver cytokine
A
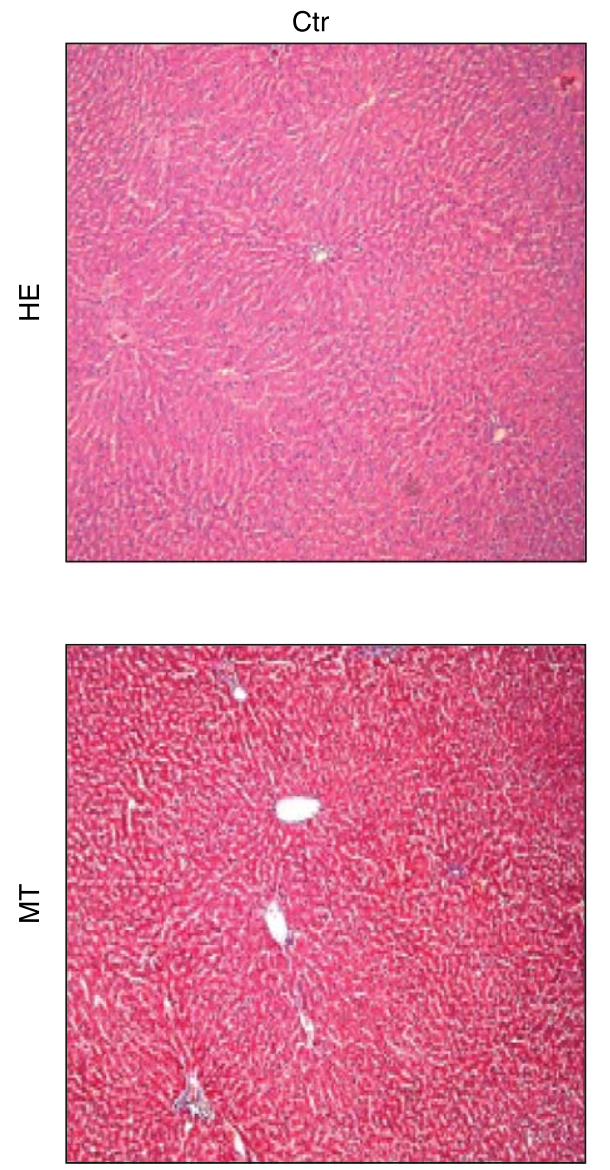

$\mathrm{HL}$
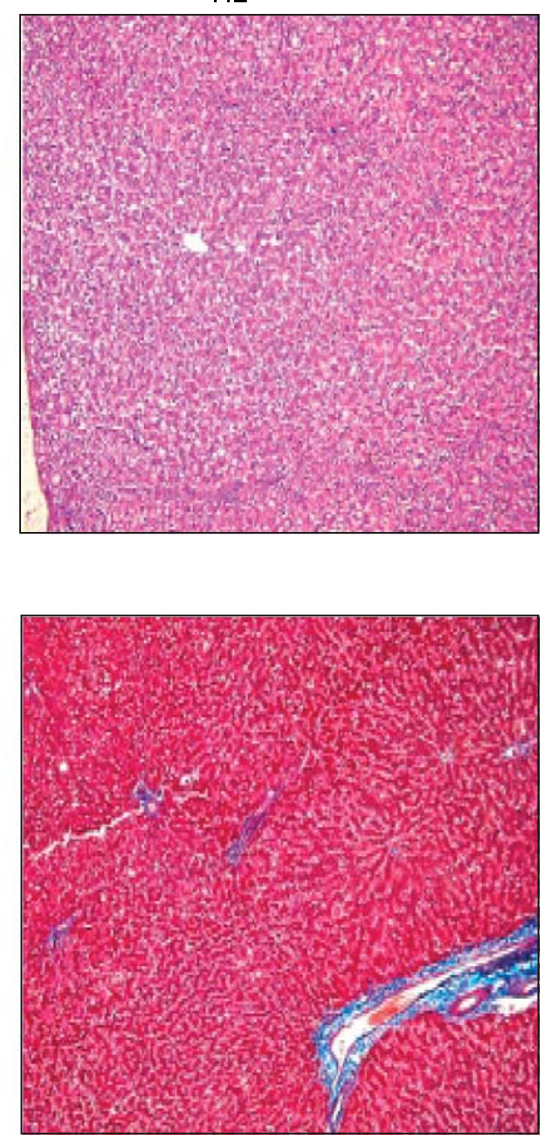

Figure 1 (continued) 

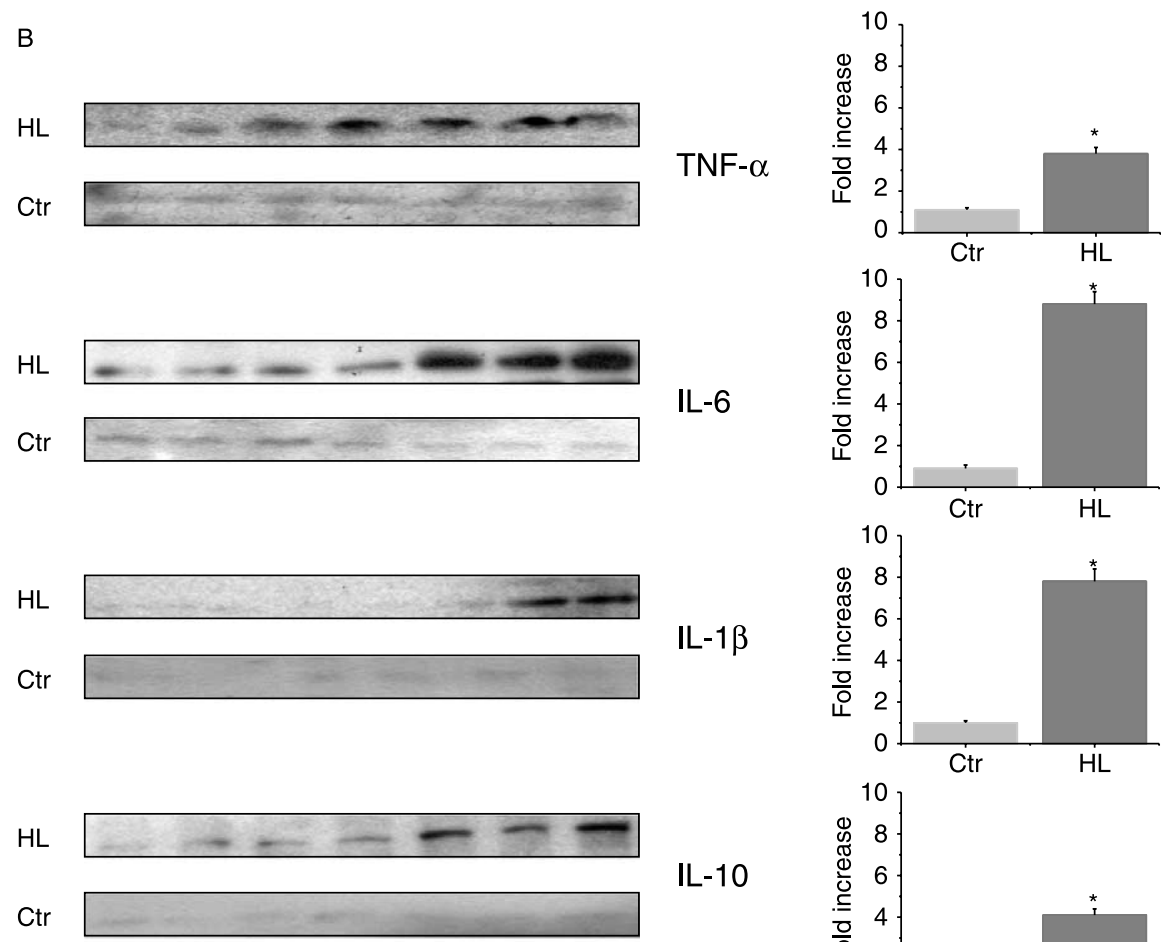

\section{$\mathrm{IL}-1 \beta$}

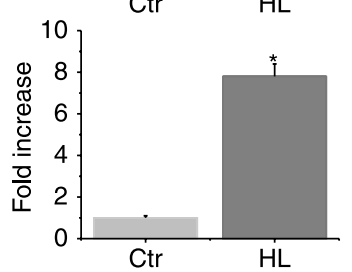

IL-10
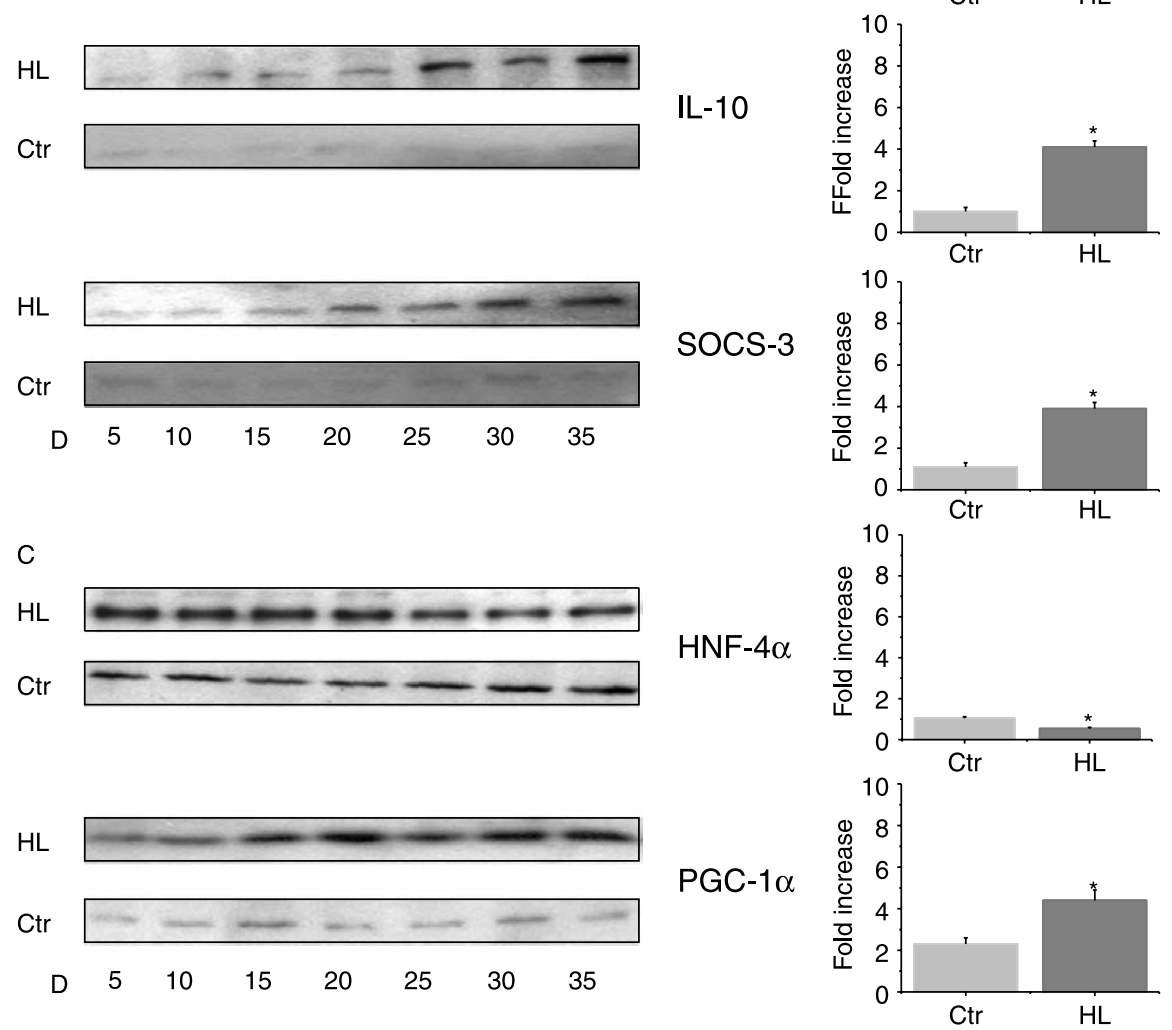

Figure 1 Effects of high-fat feeding on liver histology and protein content. (A) Hematoxylin-eosin (HE) and Masson's trichrome (MT) staining of $5 \cdot 0 \mu \mathrm{m}$ sections of livers of Wistar rats fed on a standard diet (Ctr) or a fat-rich diet (HL) for 35 days. (B) The protein amounts of TNF- $\alpha$, IL-6, IL$1 \beta$, IL-10, and SOCS-3 were determined by immunoblotting in samples from livers of Wistar rats fed on a standard diet (Ctr) or a fat-rich diet $(\mathrm{HL})$ after 5-35 days (D) of feeding with respective diets. The graphs on the right-hand side depict the respective fold variation in protein content from day 5 to day 35 in each experimental condition. (C) The protein amounts of HNF- $4 \alpha$ and PGC- $1 \alpha$ were determined by immunoblotting in samples from livers of Wistar rats fed on a standard diet (Ctr) or a fat-rich diet (HL) after 5-35 days. The graphs on the righthand side depict the respective fold variation of protein content from day 5 to day 35 in each experimental condition. In $A$, the figures are representative of five different experiments. In B and C, $n=5, * P<0 \cdot 05$ versus Ctr. Results are presented as means \pm S.E.M. 
A

\begin{tabular}{|c|c|c|c|c|c|c|}
\hline 0 & 10 & 50 & م & $2^{0}$ & $\alpha^{0}$ & INF $(\mu \mathrm{g} / 100 \mu \mathrm{l})$ \\
\hline$\pi$ & 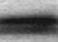 & & & & & P-JNK \\
\hline
\end{tabular}

B

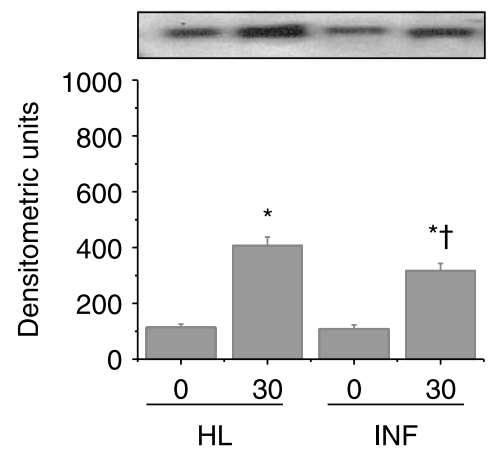

TNF- $\alpha$
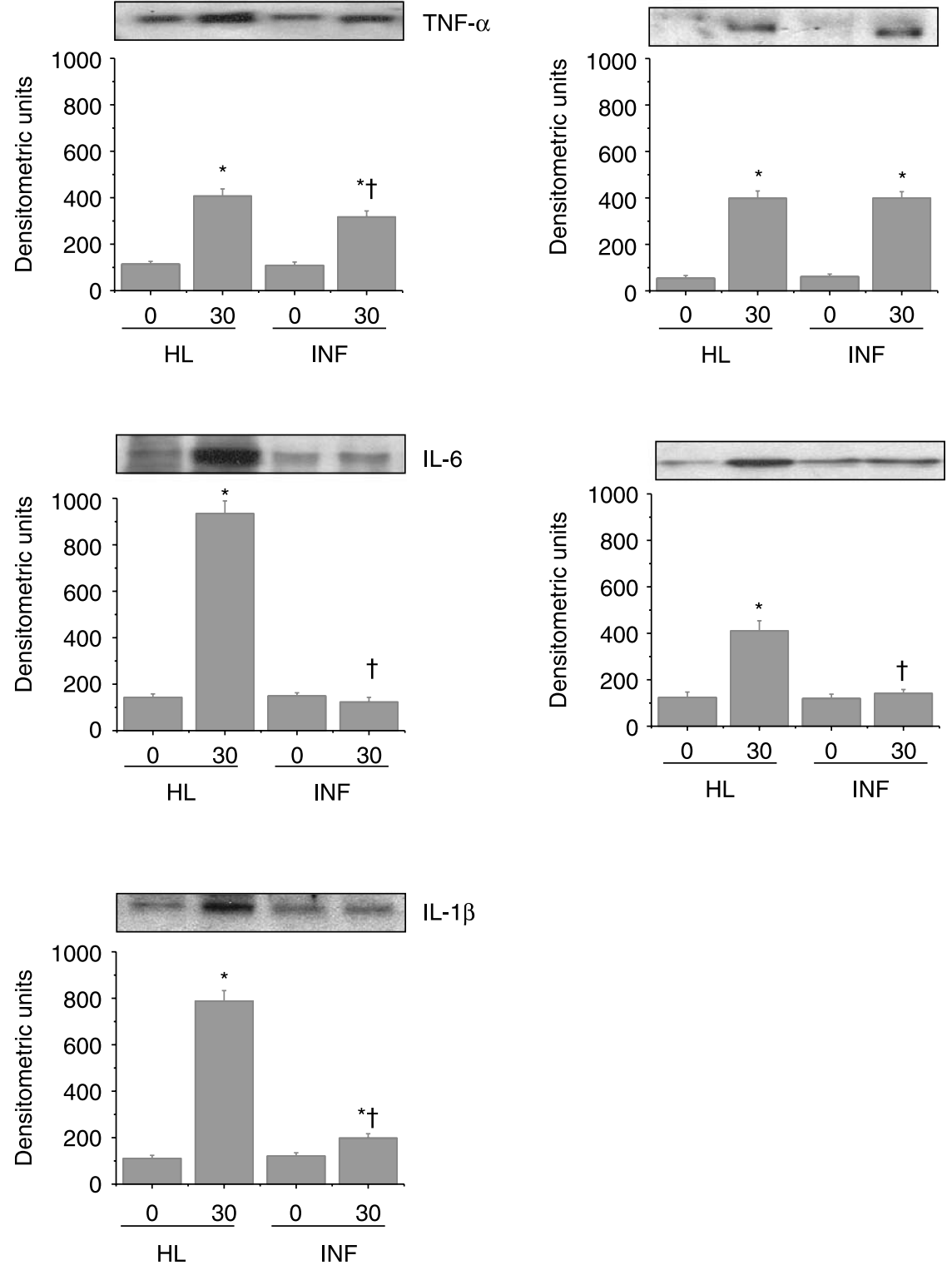

Figure 2 Effects of infliximab on TNF- $\alpha$ signaling and cytokine expression. (A) Rats were treated intraperitoneally with a single dose of infliximab (as depicted in figure), and after $24 \mathrm{~h}$, liver was obtained for immunoblot using anti-pJNK antibody. (B) The protein amounts of TNF- $\alpha$, IL-6, IL-1 $\beta$, IL-10, and SOCS-3 were determined by immunoblotting in samples from livers of Wistar rats fed on a fat-rich diet and treated with saline (HL) or infliximab (INF) for 10 days. Samples were collected at day 0 (before specific diet introduction) or at day 30 (30 days after specific diet introduction and 10 days after beginning daily treatment with saline or infliximab). In all experiments, $n=5,{ }^{*} P<0.05$ versus time 0 in the same condition; ${ }^{\dagger} P<0.05$ versus time 35 in $\mathrm{HL}$. Results are presented as means \pm S.E.M. 
expression and pro-inflammatory activation, rats were treated for 10 days (beginning on day 20 of HL diet) with the TNF- $\alpha$ blocking monoclonal antibody infliximab, and at the end of the experimental period, fragments of liver were obtained for immunoblotting experiments. As shown in Fig. 2B, infliximab promoted a significant reduction in IL-6 expression, which returned to levels similar to those of the control. Infliximab also promoted a significant reduction in IL- $1 \beta$ and TNF- $\alpha$ expression, but in these cases, the reductions were only partial. The levels of the regulatory cytokine, IL-10, were not affected by infliximab; however, the levels of the suppressor of cytokine signaling, SOCS-3, were completely restored to basal levels.

\section{Infliximab reduces liver steatosis and fibrosis in HL rats}

The treatment of $\mathrm{HL}$ rats with infliximab significantly reduced fat liver depots, as evaluated by HE staining (Fig. 3A, upper panels, HE) and determination of liver lipid content. In morphometric analyses, the magnitude of the fat area reduction was $14 \cdot 3 \pm 2 \cdot 0$-fold $(P<0 \cdot 05, n=5)$, while liver lipid content reduced from $28 \cdot 3 \pm 3 \cdot 1 \mathrm{~g} / 100 \mathrm{~g}$ to $6 \cdot 8 \pm 2 \cdot 0 \mathrm{~g} / 100 \mathrm{~g}$ $(P<0 \cdot 05, n=5)$. This was accompanied by a significant reduction in the fibrosis area $(2 \cdot 3 \pm 0 \cdot 4$-fold; $P<0 \cdot 05, n=5$; Fig. 3A, lower panels, MT). In addition, treatment with infliximab resulted in stabilization of HNF- $4 \alpha$ levels, and reduction of PGC- $1 \alpha$ expression, which returned to basal levels.

\section{Infliximab improves insulin signal transduction in livers of $H L$ rats}

Since liver insulin resistance is one of the hallmarks of diet-induced steatohepatitis, we evaluated the effect of infliximab on insulin signaling through the IR/IRS1/IRS2/Akt/FOXO1 and JAK2/STAT3 pathways. For this, rats fed on a standard (not shown) or HL diet, treated or not with infliximab, were used in immunoprecipitation and immunoblotting experiments. As compared with rats fed on a standard diet, HL feeding promoted a significant reduction in insulininduced activation of IR, IRS1, IRS2, Akt, and FOXO1 (not shown; previously studied (De Souza et al. 2005b)). As shown in Fig. 4A, infliximab treatment significantly improved insulin-induced IR, IRS1, and IRS2 tyrosine phosphorylation, and Akt and FOXO1 serine phosphorylation. These effects were not accompanied by changes in respective protein content (not shown). In addition, infliximab treatment improved insulin-induced tyrosine phosphorylation of JAK2 and STAT3 (Fig. 4B); these effects were not accompanied by changes in respective protein content (results not shown). Finally, as a consequence of improved insulin action in liver, the glycogen content in this organ increased from $54 \cdot 3 \pm$ $4 \cdot 2 \mathrm{mg} / 100 \mathrm{~g}$ to $91 \cdot 0 \pm 4 \cdot 8 \mathrm{mg} / 100 \mathrm{~g}(P<0 \cdot 05, n=5)$.

\section{Discussion}

Currently, one of the most important challenges regarding NAFLD research is to understand why some patients with steatosis evolve to pre-cirrhotic conditions, such as NASH and fibrosis, while others remain stable with the rather benign state of steatosis (Day \& James 1998, Tilg \& Diehl 2000). Three events seem to play an important role in this progression, the consumption of fat-rich diets, the activation of proinflammatory signaling, and the development of liver insulin resistance (Day \& James 1998, Tilg \& Diehl 2000).

With regard to the activation of inflammatory signaling, it has become clear that systemic and locally produced cytokines are required to drive the progression from steatosis to NASH, fibrosis and cirrhosis (Day \& James 1998, Tilg \& Diehl 2000, Browning \& Horton 2004, Larter \& Farrell 2006). However, it is important to mention that no study, so far, has provided conclusive evidence of the role played by cytokines and other inflammatory factors in the initiation of steatosis (Tilg \& Diehl 2000, Angulo 2002). Among the various cytokines potentially involved in this process, TNF- $\alpha$ has emerged as a key inducer of nutrient- and obesity-associated NASH (Tilg \& Diehl 2000). TNF- $\alpha$ is capable of inducing the activation of stellate cells, matrix gene expression, and matrix remodeling, all of these being events that take place during the installation of NASH (Tomita et al. 2006). Interestingly, in addition to acting as an activator of liver inflammation and lesion, TNF- $\alpha$ can also promote insulin resistance by activating intracellular serine kinases, particularly JNK and IKBK, which can target and inhibit important substrates of the insulin signaling pathway (Cai et al. 2005, Diehl et al. 2005). Thus, it seems that TNF- $\alpha$ plays a central role in steatohepatitis, potentially integrating purely inflammatory signals with metabolic ones. As such, therapeutic

Table 3 Effects of infliximab treatment on metabolic parameters and tumour necrosis factor (TNF)- $\alpha$ blood levels

\begin{tabular}{|c|c|c|c|c|}
\hline & \multicolumn{2}{|l|}{ Control } & \multicolumn{2}{|l|}{ HL } \\
\hline & SAL & INF & SAL & INF \\
\hline Body mass (g) & $214 \pm 21$ & $208 \pm 16$ & $282 \pm 18$ & $270 \pm 23$ \\
\hline Insulin (ng/ml) & $2 \cdot 49 \pm 0 \cdot 40$ & $2 \cdot 41 \pm 0 \cdot 57$ & $3 \cdot 39 \pm 0 \cdot 37$ & $3 \cdot 12 \pm 0 \cdot 30$ \\
\hline Leptin (ng/ml) & $2 \cdot 99 \pm 0.45$ & $2 \cdot 87 \pm 0 \cdot 25$ & $3 \cdot 91 \pm 0 \cdot 24$ & $3 \cdot 78 \pm 0 \cdot 31$ \\
\hline TNF- $\alpha(p g / m l)$ & $76 \cdot 3 \pm 6 \cdot 9$ & NT & $166 \cdot 0 \pm 9 \cdot 7$ & $107 \cdot 4 \pm 8 \cdot 1 *$ \\
\hline
\end{tabular}

$N=5 ;{ }^{*} P<0 \cdot 05$ versus $\mathrm{HL}(\mathrm{SAL}) . \mathrm{SAL}$, saline treated; INF, infliximab treated. 
A
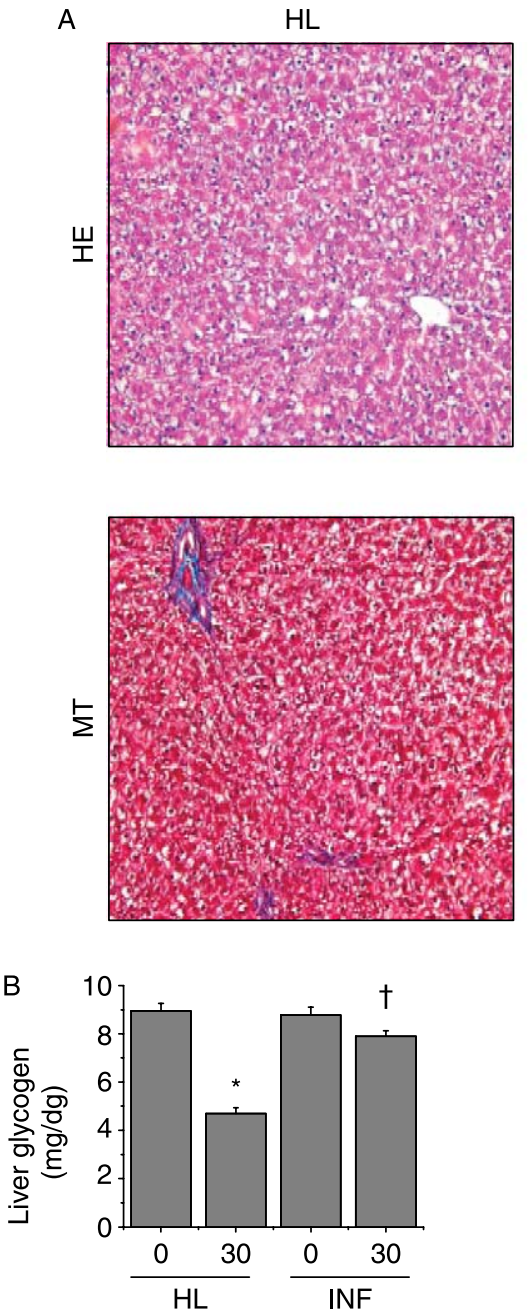

C

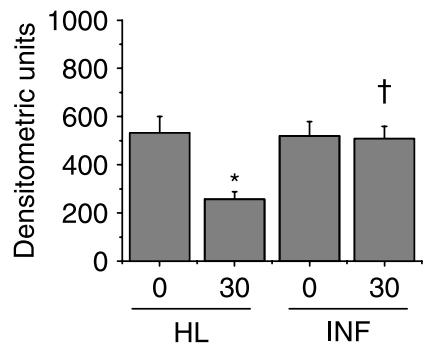

INF
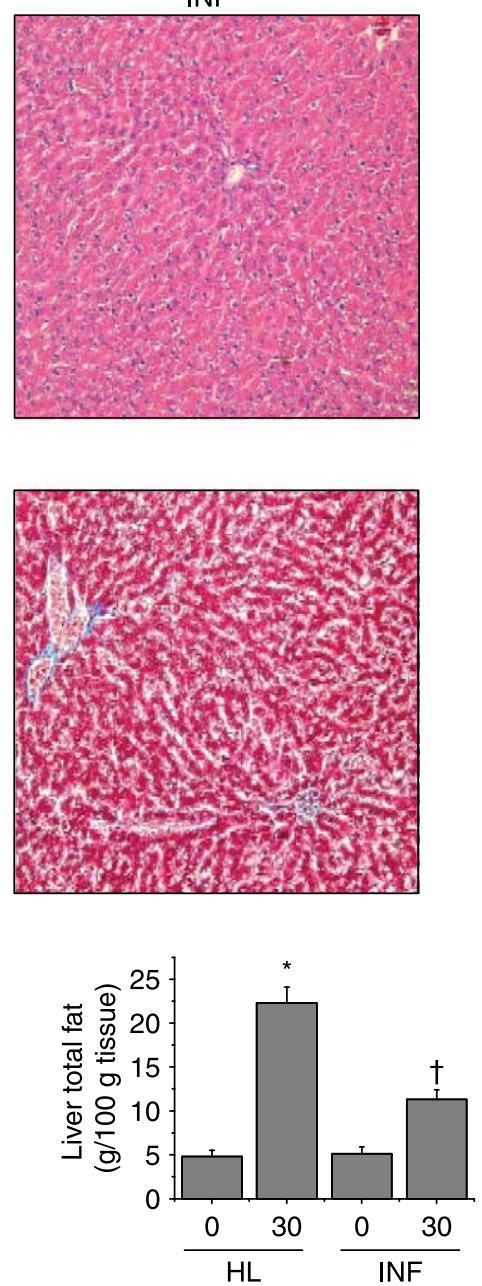

$\mathrm{HNF}-4 \alpha$

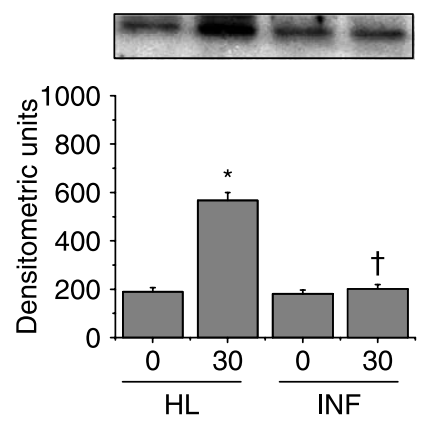

Figure 3 Effects of infliximab on liver histology and protein content. (A) Hematoxylin-eosin (HE) and Masson's trichrome (MT) staining of $5 \cdot 0 \mu \mathrm{m}$ sections of livers of Wistar rats fed on a fat-rich diet for 30 days and treated for 10 days with saline (HL) or infliximab (INF). (B) Glycogen and total fat content in liver of Wistar rats fed on a fat-rich diet for 30 days and treated for 10 days with saline (HL) or infliximab (INF). (C) The protein amounts of HNF- $4 \alpha$ and PGC- $1 \alpha$ were determined by immunoblotting in samples from livers of Wistar rats fed on a fat-rich diet and treated with saline $(\mathrm{HL})$ or infliximab (INF) for 10 days. Samples were collected on day 0 (before specific diet introduction) or on day 30 (30 days after specific diet introduction and 10 days after beginning daily treatment with saline or infliximab). In $A$, the figures are representative of five different experiments. In $\mathrm{B}, n=5, * P<0.05$ versus time 0 in the same condition; ${ }^{+} P<0.05$ versus time 35 in HL. Results are presented as means \pm S.E.M. 
A
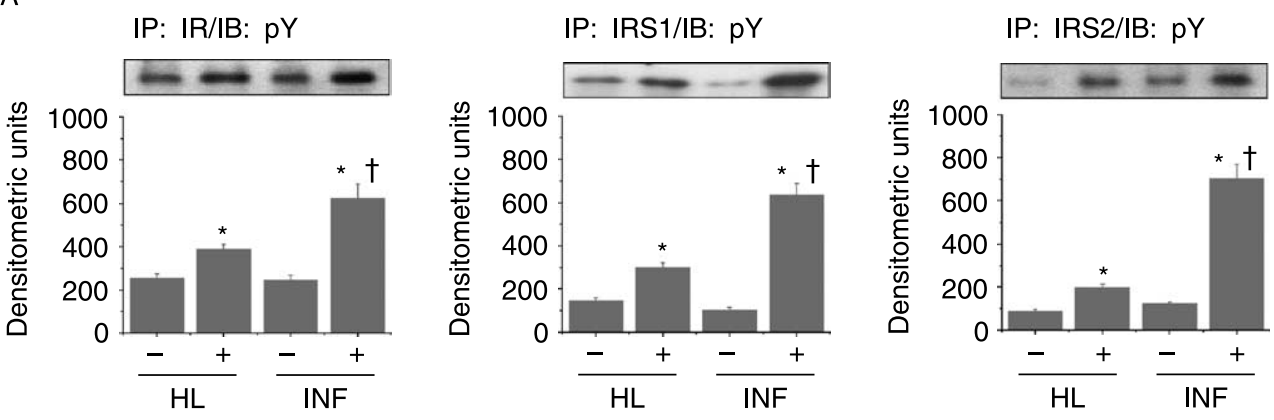

IB: pAkt

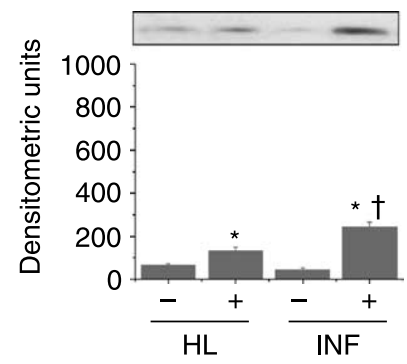

IB: pFOXO1

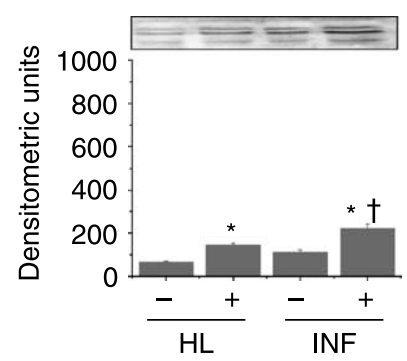

B

IP: JAK2/IB: pY

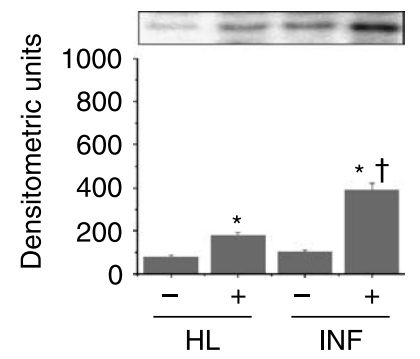

IB: pSTAT3

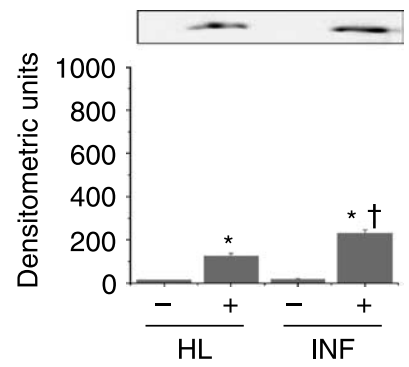

Figure 4 Effects of infliximab on insulin signal transduction in the liver of rats fed on a high-fat diet. Wistar rats fed on a high-fat diet for 0 or 30 days and treated with saline (HL) or infliximab (INF) during the last 10 days (from day 20 to day 30$)$ were anesthetized and acutely treated through the cava vein with saline $(100 \mu \mathrm{l})(-)$ or insulin $\left(100 \mu \mathrm{l}, 10^{-6} \mathrm{~mol} / \mathrm{l}\right)(+)$. After 5 (IR, IRS1, and IRS2 in A; JAK2 in B), 10 (Akt in A), or 20 (FOXO1 in A; STAT3 in B) min, fragments were obtained from the liver and used in immunoprecipitation and immunoblotting experiments. In immunoprecipitation experiments, samples containing $2.0 \mathrm{mg}$ total protein extracts were incubated with respective antibodies (IP), and immunocomplexes recovered with protein a sepharose were separated, under denaturing conditions, by SDS-PAGE. Nitrocellulose transfers were blotted (IB) with anti-phosphotyrosine antibodies $(\mathrm{pY})$. In direct immunoblotting experiments, samples containing $0 \cdot 2 \mathrm{mg}$ total protein were separated by SDS-PAGE, transferred to nitrocellulose membranes, and blotted (IB) with respective antibodies. The bar graphs represent means \pm S.E.M. of densitometric values obtained for the bands. In all experiments, $n=5$; ${ }^{*} P<0 \cdot 05$ vs $(-)$ in the same condition; ${ }^{\dagger} P<0 \cdot 05$ vs $(+)$ in $\mathrm{HL}$.

strategies aiming at inhibiting TNF- $\alpha$ activity in the liver have emerged as potentially effective approaches to treat NAFLD (Tilg \& Diehl 2000).

In the present study, we evaluated the effect of the antiTNF- $\alpha$ monoclonal antibody, infliximab, upon liver steatosis, fibrosis, and insulin signal transduction in an animal model fed on a high-fat diet (De Souza et al. 2005a; Pitombo et al. 2006). Infliximab has been widely tested in humans and animal models with different inflammatory diseases, and it is known to produce a sustained anti-inflammatory effect (Siegel et al. 1995, Arend 2002). Initially, we determined the timedependent ability of the diet to promote liver expression of proinflammatory markers and induce steatosis and fibrosis. After 20 days on the HL diet, higher expressions of TNF- $\alpha$, IL-6, IL-1 $\beta$, IL-10, and SOCS-3 were detected. This was accompanied by an increased expression of a co-activator of 
gene transcription involved in hepatic lipid oxidation, PGC$1 \alpha$, and by a reduction in the expression of a transcription factor, involved in gluconeogenesis, HNF- $4 \alpha$. In addition, the HL diet led to a significant increase in liver fat deposition and also to a significant increase in liver fibrosis. With regard to the induction of liver steatosis and fibrosis and the modulation of expression of PGC- $1 \alpha$ and HNF- $4 \alpha$, these are well-known outcomes of nutrient-induced liver dysfunction and serve to validate the model (De Souza et al. 2005b). However, the determination of a time course of expression of inflammatory markers is original and shows that, in this particular model, a rather short period of treatment with a fatrich diet is capable of inducing an inflammatory response.

The treatment with infliximab led to a significant reduction of the basal activation status of the pro-inflammatory signaltransducing protein JNK and a reduction of blood TNF- $\alpha$ levels. In addition, the treatment led to a reduction of $40 \%$ in TNF- $\alpha$ expression in liver. This is in pace with reductions observed in other studies. For example, in an animal model of colitis, the treatment with a dose of infliximab, which is similar to the one used in our study, promoted a $45 \%$ decrease in local (colonic) levels of TNF- $\alpha$ and a 50\% reduction in blood levels of the cytokine (Woodruff et al. 2003). Furthermore, infliximab treatment effectively inhibited the expression of the proinflammatory cytokines, IL-6, and IL- $1 \beta$, while the antiinflammatory cytokine IL-10 was not affected by the treatment. The maintenance of higher levels of IL-10 may have a positive impact on the overall result of the treatment, as suggested by recent studies that show a protective effect of this cytokine in NASH development (den Boer et al. 2006, Elinav et al. 2006). Another outcome of the treatment with infliximab was the reduction of SOCS-3 expression. SOCS-3 is an intracellular modulator of proinflammatory signaling that is induced by a number of cytokines and hormones that employ the JAK/STAT signaling system (Kubo et al. 2003). SOCS-3 can either physically interact with the JAK/STAT complex or drive signaling intermediaries to proteosome degradation resulting, in both cases, in the negative regulation of signal transduction (Kubo et al. 2003, Balasubramanyam et al. 2005). The reduction of its expression after infliximab treatment indicates that proinflammatory signaling was considerably reduced by this approach.

In parallel with the reduction in the expression of inflammatory markers in the liver, infliximab significantly reduced steatosis and fibrosis, which was accompanied by a reduction in PGC- $1 \alpha$ and an increase in HNF- $4 \alpha$ expression. The effect of infliximab on steatosis was so remarkable that even upon macroscopic evaluation of the liver it could be noticed. Since insulin action favors fat deposition, one could argue that the improvement of insulin activity in the liver promoted by infliximab should increase and not reduce steatosis. However, it must be emphasized that liver insulin resistance affects differently two of the main physiological phenomena controlled by insulin in this tissue, i.e. gluconeogenesis and fat $\beta$-oxidation/deposition. While gluconeogenesis and $\beta$-oxidation become impaired quite early during the installation of insulin resistance, triglyceride synthesis and deposition are affected only in late stage insulin resistance (Silverman et al. 1990, Baig et al. 2001); this implies on greater deposition of triglyceride, which is reversed as soon as insulin resistance is controlled.

Finally, to determine the effect of TNF- $\alpha$ inhibition upon liver insulin action, we evaluated insulin signal transduction through the IR/IRS1/IRS2/Akt/FOXO1 and JAK2/ STAT3 signaling pathways. The first is the classical pathway activated by insulin in all insulin-responsive tissues (Saltiel \& Kahn 2001). In liver, this pathway is responsible for the connection of the insulin signal with the control of gluconeogenesis (Saltiel \& Kahn 2001). The outstanding improvement in the molecular activation of this pathway, achieved with infliximab, may be the result of an alleviation of the functional activities of serine kinases, such as JNK and I $\kappa \mathrm{BK}$, which are targets of TNF- $\alpha$ and can affect insulin signaling by promoting the inhibitory serine phosphorylation of IR, IRS1, and IRS-2 (Paz et al. 1997, Hirosumi et al. 2002, Araujo et al. 2005). The JAK2/STAT3 is a non-classical target of insulin signaling (Saad et al. 1996) that participates in the crosstalk of the insulin signaling with several other pathways (Calegari et al. 2005, Velloso et al. 2006), including inflammatory pathways activated by cytokines. In addition, the JAK2/STAT3 pathway is a primary target for leptin signaling, a hormone known to exert anti-steatotic effects (Lee et al. 2001) and to be modulated by a crosstalk with insulin (Carvalheira et al. 2003). In liver, STAT-3 is known to inhibit SREBP-1c and, thus, to impose a negative signal in hepatic lipogenesis (Ueki et al. 2004). The inhibition of insulininduced activation of STAT-3 in the liver of HL rats suggests that lipogenesis could be stimulated through this pathway. The reduction in SOCS-3 expression, accompanied by improved insulin-induced activation of JAK2/STAT-3 signaling after infliximab treatment may have played a positive role in the reduction of fat liver deposition and of fibrosis. Although we have not evaluated the clinical outcomes of the modification of insulin action in liver, as for example, determining liver glucose production, the comprehensive study of the signaling pathways herein performed, strongly suggests that insulin action was indeed improved by infliximab treatment.

In conclusion, the present study provides further evidence for a role for TNF- $\alpha$ as an attractive target for the therapeutics of NAFLD. Inhibition of TNF- $\alpha$ by the commercially available monoclonal antibody, infliximab, resulted not only in reversal of steatosis and fibrosis, but also in the improvement of insulin signal transduction.

\section{Acknowledgements}

This work was supported by Fundação de Amparo à Pesquisa do Estado de São Paulo (FAPESP) and Conselho Nacional de Desenvolvimento Cientifico e Tecnológico (CNPq). We are indebted to Dr N Conran for English editing. The authors declare that there is no conflict of interest that would prejudice the impartiality of this scientific work. 


\section{References}

Angulo P 2002 Nonalcoholic fatty liver disease. New England Journal of Medicine 346 1221-1231.

Anty R, Bekri S, Luciani N, Saint-Paul MC, Dahman M, Iannelli A, Amor IB, Staccini-Myx A, Huet PM, Gugenheim J et al. 2006 The inflammatory C-reactive protein is increased in both liver and adipose tissue in severely obese patients independently from metabolic syndrome, Type 2 diabetes, and NASH. American Journal of Gastroenterology 101 1824-1833.

Araujo EP, De Souza CT, Gasparetti AL, Ueno M, Boschero AC, Saad MJ \& Velloso LA 2005 Short-term in vivo inhibition of insulin receptor substrate-1 expression leads to insulin resistance, hyperinsulinemia, and increased adiposity. Endocrinology 146 1428-1437.

Araujo de Vizcarrondo C, Carrillo de Padilla F \& Martin E 1998 Fatty acid composition of beef, pork, and poultry fresh cuts, and some of their processed products. Archivos Latinoamericanos de Nutricion 48 354-358.

Arend WP 2002 The mode of action of cytokine inhibitors. Journal of Rheumatology 65 16-21.

Baig NA, Herrine SK \& Rubin R 2001 Liver disease and diabetes mellitus. Clinics in Laboratory Medicine 21 193-207.

Balasubramanyam M, Sampathkumar R \& Mohan V 2005 Is insulin signaling molecules misguided in diabetes for ubiquitin-proteasome mediated degradation? Molecular and Cellular Biochemistry 275 117-125.

den Boer MA, Voshol PJ, Schroder-van der Elst JP, Korsheninnikova E, Ouwens DM, Kuipers F, Havekes LM \& Romijn JA 2006 Endogenous interleukin-10 protects against hepatic steatosis but does not improve insulin sensitivity during high-fat feeding in mice. Endocrinology 147 4553-4558.

Browning JD \& Horton JD 2004 Molecular mediators of hepatic steatosis and liver injury. Journal of Clinical Investigation 114 147-152.

Browning JD, Szczepaniak LS, Dobbins R, Nuremberg P, Horton JD, Cohen JC, Grundy SM \& Hobbs HH 2004 Prevalence of hepatic steatosis in an urban population in the United States: impact of ethnicity. Hepatology $\mathbf{4 0}$ 1387-1395.

Cai D, Yuan M, Frantz DF, Melendez PA, Hansen L, Lee J \& Shoelson SE 2005 Local and systemic insulin resistance resulting from hepatic activation of IKK-beta and NF-kappaB. Nature Medicine 11 183-190.

Calegari VC, Alves M, Picardi PK, Inoue RY, Franchini KG, Saad MJ \& Velloso LA 2005 Suppressor of cytokine signaling-3 Provides a novel interface in the cross-talk between angiotensin II and insulin signaling systems. Endocrinology 146 579-588.

Carvalheira JB, Ribeiro EB, Folli F, Velloso LA \& Saad MJ 2003 Interaction between leptin and insulin signaling pathways differentially affects JAKSTAT and PI 3-kinase-mediated signaling in rat liver. Biological Chemistry 384 151-159.

Chang JT \& Lichtenstein GR 2006 Drug insight: antagonists of tumornecrosis factor-alpha in the treatment of inflammatory bowel disease. Nature Clinical Practice. Gastroenterology and Hepatology 3 220-228.

Day CP \& James OF 1998 Steatohepatitis: a tale of two 'hits'? Gastroenterology 114 842-845.

Diehl AM, Li ZP, Lin HZ \& Yang SQ 2005 Cytokines and the pathogenesis of non-alcoholic steatohepatitis. Gut $\mathbf{5 4}$ 303-306.

Elinav E, Pappo O, Sklair-Levy M, Margalit M, Shibolet O, Gomori M, Alper R, Thalenfeld B, Engelhardt D, Rabbani E et al. 2006 Amelioration of nonalcoholic steatohepatitis and glucose intolerance in ob/ob mice by oral immune regulation towards liver-extracted proteins is associated with elevated intrahepatic NKT lymphocytes and serum IL-10 levels. Journal of Pathology 208 74-81.

Hirosumi J, Tuncman G, Chang L, Gorgun CZ, Uysal KT, Maeda K, Karin M \& Hotamisligil GS 2002 A central role for JNK in obesity and insulin resistance. Nature $\mathbf{4 2 0}$ 333-336.

Hotamisligil GS 2006 Inflammation and metabolic disorders. Nature 444 860-867.

Iimuro Y, Gallucci RM, Luster MI, Kono H \& Thurman R G 1997 Antibodies to tumor necrosis factor alfa attenuate hepatic necrosis and inflammation caused by chronic exposure to ethanol in the rat. Hepatology 26 1530-1537.

Kubo M, Hanada T \& Yoshimura A 2003 Suppressors of cytokine signaling and immunity. Nature Immunology 4 1169-1176.
Larter CZ \& Farrell GC 2006 Insulin resistance, adiponectin, cytokines in NASH: Which is the best target to treat? Journal of Hepatology 44 253-261. Lee Y, Wang MY, Kakuma T, Wang ZW, Babcock E, McCorkle K, Higa M, Zhou YT \& Unger RH 2001 Unger RH, Liporegulation in diet-induced obesity, The antisteatotic role of hyperleptinemia. Journal of Biological Chemistry 276 5629-5635.

Lieber CS, Leo MA, Mak KM, Xu Y, Cao Q, Ren C, Ponomarenko A \& DeCarli LM 2004 Model of nonalcoholic steatohepatitis. American Journal of Clinical Nutrition 79 502-509.

Lin XZ, Horng MH, Sun YN, Shiesh SC, Chow NH \& Guo XZ 1998 Computer morphometry for quantitative measurement of liver fibrosis: comparison with Knodell's score, colorimetry and conventional description reports. Journal of Gastroenterology and Hepatology 13 75-80.

Mackenzie CG, Mackenzie JB, Reiss OK \& Wisneski JA 1970 Identification of albumin-bound fatty acids as the major factor in serum-induced lipid accumulation by cultured cells. Journal of Lipid Research 11 571-582.

Medina J, Fernandez-Salazar LI, Garcia-Buey L \& Moreno-Otero R 2004 Approach to the pathogenesis and treatment of nonalcoholic steatohepatitis. Diabetes Care 27 2057-2066.

Paz K, Hemi R, LeRoith D, Karasik A, Elhanany E, Kanety H \& Zick Y 1997 A molecular basis for insulin resistance, Elevated serine/threonine phosphorylation of IRS-1 and IRS-2 inhibits their binding to the juxtamembrane region of the insulin receptor and impairs their ability to undergo insulin-induced tyrosine phosphorylation. Journal of Biological Chemistry 272 29911-29918.

Pimenta WP, Saad MJ, Paccola GM, Piccinato CE \& Foss MC 1989 Effect of oral glucose on peripheral muscle fuel metabolism in fasted men. Brazilian Journal of Medical and Biological Research 22 465-476.

Pitombo C, Araujo EP, De Souza CT, Pareja JC, Geloneze B \& Velloso LA 2006 Amelioration of diet-induced diabetes mellitus by removal of visceral fat. Journal of Endocrinology 191 699-706.

Poniachik J, Csendes A, Diaz JC, Rojas J, Burdiles P, Maluenda F, Smok G, Rodrigo R \& Videla LA 2006 Increased production of IL-1alpha and TNF-alpha in lipopolysaccharide-stimulated blood from obese patients with non-alcoholic fatty liver disease. Cytokine 33 252-257.

Saad MJ, Carvalho CR, Thirone AC \& Velloso LA 1996 Insulin induces tyrosine phosphorylation of JAK2 in insulin-sensitive tissues of the intact rat. Journal of Biological Chemistry 271 22100-22104.

Saltiel AR \& Kahn CR 2001 Insulin signalling and the regulation of glucose and lipid metabolism. Nature $\mathbf{4 1 4}$ 799-806.

Scott DL \& Kingsley GH 2006 Tumor necrosis factor inhibitors for rheumatoid arthritis. New England Journal of Medicine 355 704-712.

Scott AM, Atwater I \& Rojas E 1981 A method for the simultaneous measurement of insulin release and B cell membrane potential in single mouse islets of Langerhans. Diabetologia 21 470-475.

Siegel SA, Shealy DJ, Nakada MT, Le J, Woulfe DS, Probert L, Kollias G, Ghrayeb J, Vilcek J \& Daddona PE 1995 The mouse/human chimeric monoclonal antibody cA2 neutralizes TNF in vitro and protects transgenic mice from cachexia and TNF lethality in vivo. Cytokine 7 15-25.

Silverman JF, O’Brien KF, Long S, Leggett N, Khazanie PG, Pories WJ, Norris HT \& Caro JF 1990 Liver pathology in morbidly obese patients with and without diabetes. American Journal of Gastroenterology 85 1349-1355.

De Souza CT, Araujo EP, Bordin S, Ashimine R, Zollner RL, Boschero AC, Saad MJ \& Velloso LA 2005a Consumption of a fat-rich diet activates a proinflammatory response and induces insulin resistance in the hypothalamus. Endocrinology 146 4192-4199.

De Souza CT, Araujo EP, Prada PO, Saad MJ, Boschero AC \& Velloso LA $2005 b$ Short-term inhibition of peroxisome proliferator-activated receptorgamma coactivator-1alpha expression reverses diet-induced diabetes mellitus and hepatic steatosis in mice. Diabetologia 48 1860-1871.

Spahr L, Rubbia-Brandt L, Frossard JL, Giostra E, Rougemont AL, Pugin J, Fischer M, Egger H \& Hadengue A 2002 Combination of steroids with infliximab or placebo in severe alcoholic hepatitis: a randomized controlled pilot study. Journal of Hepatology 37 448-455.

Thirone AC, Scarlett JA, Gasparetti AL, Araujo EP, Lima MH, Carvalho CR, Velloso LA \& Saad MJ 2002 Modulation of growth hormone signal transduction in kidneys of streptozotocin-induced diabetic animals: effect of a growth hormone receptor antagonist. Diabetes $\mathbf{5 1} 2270-2281$. 
Tilg H \& Diehl AM 2000 Cytokines in alcoholic and nonalcoholic steatohepatitis. New England Journal of Medicine 343 1467-1476.

Tomita K, Tamiya G, Ando S, Ohsumi K, Chiyo T, Mizutani A, Kitamura N, Toda K, Kaneko T, Horie Y et al. 2006 Tumour necrosis factor alpha signalling through activation of Kupffer cells plays an essential role in liver fibrosis of non-alcoholic steatohepatitis in mice. Gut 55 415-424.

Trinder P 1969 Determination of blood glucose using an oxidase-peroxidase system with a non-carcinogenic chromogen. Journal of Clinical Pathology 22 158-161.

Ueki K, Kondo T, Tseng YH \& Kahn CR 2004 Central role of suppressors of cytokine signaling proteins in hepatic steatosis, insulin resistance, and the metabolic syndrome in the mouse. PNAS 101 10422-10427.

Velloso LA, Kampe O, Hallberg A, Christmanson L, Betsholtz C \& Karlsson FA 1993 Demonstration of GAD-65 as the main immunogenic isoform of glutamate decarboxylase in type 1 diabetes and determination of autoantibodies using a radioligand produced by eukaryotic expression. Journal of Clinical Investigation 91 2084-2090.

Velloso LA, Folli F, Perego L \& Saad MJ 2006 The multi-faceted cross-talk between the insulin and angiotensin II signaling systems. Diabetes/Metabolism Research and Reviews 22 98-107.
Williams R 2006 Global challenges in liver disease. Hepatology 44 521-526.

Woodruff TM, Arumugam TV, Shiels IA, Reid RC, Fairlie DP \& Taylor SM 2003 A potent human C5a receptor antagonist protects against disease pathology in a rat model of inflammatory bowel disease. Journal of Immunology 171 5514-5520.

Yin M, Wheeler MD, Kono H, Bradford BU, Gallucci RM, Luster MI \& Thurman RG 1999 Essential role of tumor necrosis factor alpha in alcoholinduced liver injury in mice. Gastroenterology 117 942-952.

Zou Y, Li J, Lu C, Wang J, Ge J, Huang Y, Zhang L \& Wang Y 2006 High-fat emulsion-induced rat model of nonalcoholic steatohepatitis. Life Science 79 1100-1107.

Received in final form 11 June 2007

Accepted 13 June 2007

Made available online as an Accepted Preprint

18 June 2007 